\title{
1-(4-\{[(3,5-dimethyl-1H-pyrazol-1-yl)methyl] amino\} phenyl) ethanone
}

\section{Mohamed El Kodadi, Fouad Malek and Abdelkrim Ramdani*.}

Laboratory of Chemistry Organic-Physics, Department of Chemistry, Faculty of Sciences, University Mohammed The First, BP 524-60 000 Oujda, Morocco.

Email: elkodadi@sciences.univ-oujda.ac.ma

Received: 5 January 2003 / Accepted: 19 November 2003 / Published: 24 February 2004

Keywords: pyrazole, ligand, aminoketone.

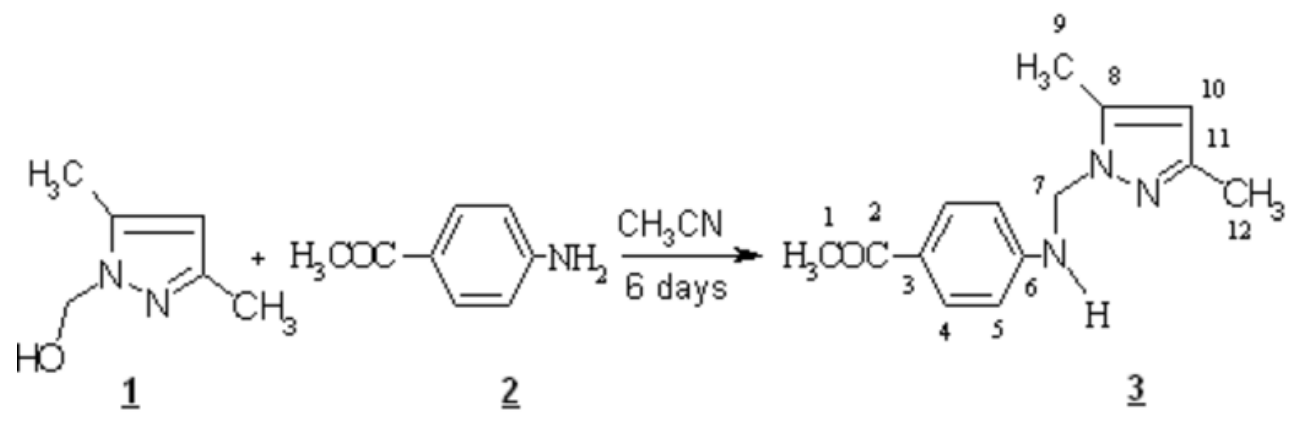

A mixture of (3,5-dimethyl-1H-pyrazol-1-yl)methanol $\underline{\mathbf{1}}$ [1] (1.86 g, $14.8 \mathrm{mmol})$ and 4-amino-acetophenone $\underline{\mathbf{2}}$ (1g, $7.4 \mathrm{mmol})$ in acetonitrile $(50 \mathrm{~mL})$ was stirred in a closed vessel at room temperature for 6 days [2, 3, 4]. The white precipitate was filtred off, washed with acetonitrile and dried in air.

Yield: (1.3g, 73\%).

Melting Point $=142-144^{\circ} \mathrm{C}\left(\mathrm{CH}_{3} \mathrm{CN}\right)$.

IR (KBr, cm ${ }^{-1}$ ): 3260(m, NH), 2900(m, -CH), 1670(s, C=O), 1580 (s, C=C), 1520(m, C-N), 1310(w), 1230(s), 1120(w), 810(w).

${ }^{1} \mathrm{H}$ NMR (400 MHz, CDCl $)$ d ppm: 7.8 (d, 2H, -CH Benz, J= $5.71 \mathrm{~Hz}$ ); 6.75 (d, 2H, -CH Benz, J= 5.71 Hz); 5.72 (s,1H, Pz); 5.45 (t, 1H,-NH, J= 3.42Hz); 5.4 (d, 2H, N-CH2-N, J=3.42 Hz); 2.48 (s, 3H, CH3 CO); 2.32 (s, 3H, $\left.\mathrm{CH}_{3}\right) ; 2.2$ (s, 3H, $\left.\mathrm{CH}_{3}\right)$.

${ }^{13} \mathrm{C}$ NMR (100 MHz, CDCl $)$ d ppm: 195.95(C2); 149.33(C6); 147.53(C4); 138.22(C3); 130.01(C5);

127.67(C8); 112.04(C11); 105.55(C10); 56.41(C7); 25.49(C1); 12.85(C9); 10.59(C12).

FAB MS: $244[\mathrm{M}+1]$.

\section{References}

1. Sorrel, T. N.; Vankai, V. A.; Garrity, M. L., Inorg. Chem., 1991, 30, 207.

2. Malachowski, M. R. ; Davidson , M. G.; Hoffman, J. N. Inorg. Chim. Acta, 1989, 157, 91.

3. Sheu, S. C.; Tien, M. J.; Cheng, M. C.; Ho, T. I.; Peng, S. M.; Lin, Y. C. J. Chem. Soc. Dalton Trans., 1995, 3503.

4. Touzani, R.; Ramdani, A.; Ben-Hadda, T.; El Kadiri, S.; Maury, O.; Le Bozec, H.; Dixneuf, P. H., 
Synth. Commun. 2001, 31, 1315.

Sample Availability : Available from the Authors.

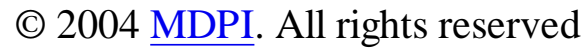

